\title{
Optical telescopes - biggest is best?
}

Sir - Twice in recent months, Nature has carried articles discussing future astronomical facilities ${ }^{1,2}$ but, although both articles mentioned 'value for money' (one in its title), no cost-benefit analysis was mentioned.

It seems strange that large sums of money are being spent on new astronomical facilities worldwide without any major cost-benefit analysis, covering both ground- and space-based observatories, to back up these investments. Abt has published a number of papers looking at some aspects of this, as have Trimble, and Martin and Irvine (see refs 3-5, for example), but it appears that noone has yet undertaken a comprehensive survey. I am trying to rectify this by undertaking a cost-benefit analysis of both ground-and space-based observatories owned by governments and other institutions in the United States and British Commonwealth countries.

I have assessed the benefit or effectiveness of a particular facility by analysing the $15 \%$ most-cited papers published in the Astrophysical Journal and Monthly Notices of the Royal Astronomical
Society every half-year from 1958 to 1994 inclusive, at four-yearly intervals, and deducing which facilities were used to produce the new observations analysed in those papers. In many cases, more than one telescope or spacecraft were used to produce the data for a given paper and, in that case, a scoring system was used ${ }^{6}$ to take into account these different facilities, the total score for each paper being unity.

The annual costs dominate the capital costs for ground-based optical/infrared observatories, and Abt found ${ }^{3}$ that these annual costs vary as the telescope aperture to the power of 2.1. Using this synthetic, I have calculated the relative cost-

effectiveness scores for different size categories of ground-based telescopes as $N_{\mathrm{p}} / \Sigma d^{2.1}$ where $N_{\mathrm{p}}$ is the number of papers produced using data from telescopes in a given size category and $\Sigma d^{2.1}$ is the sum of the diameters to the power 2.1 of all the telescopes available in that size category.

The values of $N_{\mathrm{p}} / \Sigma d^{2.1}$ have been calculated for each half-year and have then been normalized so that they total 100 in each half-year considered, to give each halfyear an equal weighting.
The average of these relative costeffectiveness scores for the second half of my period, 1978-94, was for ground-based telescopes in the above geographical area:

\begin{tabular}{lr}
$\begin{array}{l}\text { Telescope aperture } \\
\text { range } \\
\text { (in m) }\end{array}$ & $\begin{array}{r}\text { Relative } \\
\text { cost-effectiveness } \\
\text { (arbitrary units) }\end{array}$ \\
\hdashline $2.55-5.08\left(200^{\prime \prime}\right)$ & $45 \pm 6$ \\
\hdashline $1.23-2.54\left(100^{\prime}\right)$ & $33 \pm 7$ \\
\hdashline $0.62-1.22\left(48^{\prime \prime}\right)$ & $17 \pm 6$ \\
\hdashline $0.61(24 ")$ & $5+81-5$
\end{tabular}

These results clearly show that 'big is best' when looking at cutting-edge research. That is not to say that there is no role for small telescopes, but at a national level we need to build and equip the largest optical/infrared telescopes we can afford. David Leverington

Physics Department,

Open University,

Walton Hall,

Milton Keynes, MK7 6AA.

e-mail:D.Leverington@open.ac.uk

1. Reichhardt, T. et al. Nature 381, 461 (1996).

2. Nature 383, 651 (1996).

3. Abt, H.A. Publ. astr. Soc. Pac. 92, 249 (1980).

4. Trimble, V. Publ. astr. Soc. Pac. 107, 977 (1995).

5. Martin, B.R. \& Irvine, J. Res. Pol. 12, 61 (1983).

6. Leverington, D. Q. J. R. astr. Soc. 37, 643 (1996)

\section{Unequivocal spelling}

\section{for brimstone}

Sir - On the spelling of the sixteenth element of the periodic table, Morris recently drew attention to the Sanskrit 'sulvere' for sulph/fur (Nature 384, 103; 1996). While this is intriguing, as an etymological basis for modern English spelling it is a red herring.

A historical account of the development of the two spellings is given by C. A. Michie and D. R. Langslow (Br. Med. J. 297, $1697-1699$; 1988), who show that, since the early Middle Ages, only English among European languages has used the Greekderived -ph- rather than the -f- spelling. On the basis of one vote per language, therefore, the appropriate spelling for the European Union would be 'sulfur'. The relatively recent adoption of - $\mathrm{f}$ - in American English would be consistent with this.

We suggest, however, a more radical solution to discrepancies in spelling, which is to (re-)adopt the name 'brimstone', abbreviated naturally to Bs. In popular medicine, 'brimstone' was used well into this century, at least in the United Kingdom. In chemistry, elemental S would then resume its ancient name of 'brimstone', sulfuric acid would become 'brimstonic acid' $\left(\mathrm{H}_{2} \mathrm{BsO}_{4}\right)$ and concern for acid rain would recall biblical equivalents (Genesis: 19, 24 — “The Lord rained upon Sodom and upon Gomorrah brimstone and fire...") with frightening vividness.

\section{David F. Cram}

Centre for Linguistics and Philology,

University of Oxford,

Oxford, UK

W. John Cram*

Department of Biological

and Nutritional Sciences,

University of Newcastle upon Tyne.

Newcastle upon Tyne NE1 7RU, UK

e-mail:w.j.cram@ncl.ac.uk

*To whom correspondence should be addressed.

\section{A fortune awaits}

Sir - I commented some time ago (Nature $378,532 ; 1995)$ on the use of neem tree products as insecticides. Indians were at that time naturally objecting to foreign companies exploiting an indigenous Indian resource for commercial ends. The same is now happening with a yellow paste from the root of the turmeric plant, which has been used as a healing and antibiotic substance in India from time immemorial.

But those who are raising objections to foreign pharmaceutical companies exploiting turmeric for medical applications overlook its use for an entirely different purpose forgotten by Indian urban middle classes but very much alive in village India, at least here in the south. Village women assume a deep yellow over whatever parts of their skin can be seen, because the periodical application of turmeric paste keeps them free of superfluous hair. It is also an effective fungicide, fungus infections of the skin being common in tropical climates.

Unfortunately, this is a messy business, liable to stain not only skin but washbasins and bathtubs, sanitary ceramics that are unknown in the villages. The practice has therefore been discontinued and has now probably been forgotten among affluent middle-class city dwellers.

A fortune awaits the pharmacist who can isolate the active depilative in turmeric.

\section{Harry Miller}

3A Satyanarayana Avenue,

Boat Club Road,

Madras, Tamil Nadu,

India 600028

e-mail:mdsaab80@giasmd01.vsnl.net.in

corres@nature.com Letters submitted for Correspondence may be e-mailed to corres@nature.com. Do not send items intended for any other section by e-mail unless requested to do so. 